\title{
Research on Relay Protection of Distribution Network with DG
}

\author{
Xunzhe Wang \\ North China Electric Power University, Baoding 071000, China \\ wangxunzhe@tom.com
}

Keywords: Distributed generation (DG), distribution network, relay protection, PSCAD.

\begin{abstract}
As a supplement of large power grid and known as the new energy, distributed generation (DG) are developing rapidly for its convenience and environmental protection. However, after DG is connected to the distribution network, the traditional single-source radial-network will become to be a double terminal or multi-terminal power network, and the direction of the trend will change, too. This will bring a series of problems to the relay protection, such as misoperation and malfunction. Based on this, the paper analyzes the effect on protection of distribution network in different places with the DG connected. By using the electromagnetic transient simulation software PSCAD/EMTDC, this paper builds the typical model of $10 \mathrm{kV}$ distribution network to tests the theoretical analysis further. Finally the conclusion are obtained.
\end{abstract}

\section{Introduction}

For the impact on the distribution network relay protection, the traditional distribution network is based on the single-source radial-network, relay protection devices generally do not have a direction, and parameter setting is based on the three-section current protection. With distributed generation connected to the distribution network, the drawbacks of traditional relay protection cannot meet requirements, the impact to distribution network protection systems are mainly [1][2]:

Protection malfunction. When short-circuit fault occurs upstream DG, DG will provide short circuit current to the fault point, this may cause current value detected by the protection of the substation to the fault point less than the operate value and lead to protection malfunction.

Protection misoperation. When short-circuit fault occurs downstream DG, short circuit current of fault point increase due to the access of DG, might having impact on downstream protection, such as protection misoperation. Likewise, when short-circuit fault occurs upstream DG, reverse current DG provide may cause protection misoperation.

\section{Theoretical analysis}

After DG is connected to the distribution network, Power flow direction is no longer single, short circuit current will change significantly.so it will bring about a series of new problems to the traditional distribution network protection[3][4]. For simplicity, ignoring the resistance of distribution network line. Distribution network equivalent model with DG are as shown in Figure 1.

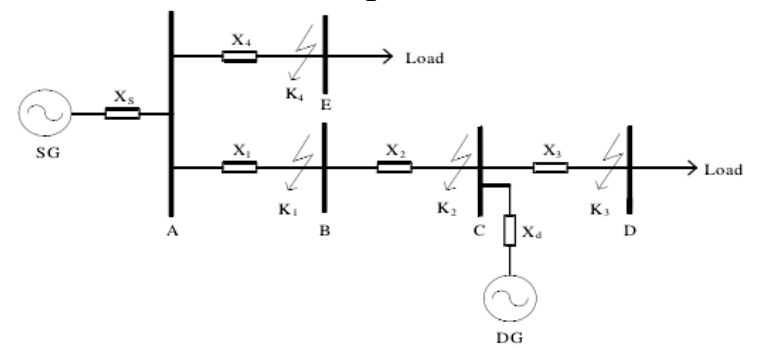

Figure 1 Distribution network equivalent model with DG

As shown in figure 1, suppose DG is connected to bus C. system capacity is $100 \mathrm{MW}$, system voltage is $E_{s}$, and System reactance is $X_{s}$,DG voltage is $E_{d}$, equivalent reactance is $X_{d}$. For simplicity, suppose that system voltage is the same as DG voltage. 
$E_{s}=E_{d}=1, X_{s}=1$, The line reactance $X_{1}=X_{2}=X_{3}=X_{4}=m X_{s}=m=5$,DG equivalent reactance $X_{d}=a X_{s}=a$, Concrete analysis as follows:

When K1 meets short circuit fault, the current through the protection QF1 and QF2 respectively are:

$$
I_{Q F 1}=\frac{1}{X_{s}+X_{1}}=\frac{1}{1+m}, I_{Q F 2}=\frac{1}{X_{d}+X_{2}}=\frac{1}{a+m}
$$

DG equivalent impedance expression is:

$$
X_{d}=x_{d g} \frac{S_{B}}{S_{D}}
$$

In the expression: $x_{d g}$ is generator transient reactance, the value is $0.25 ; S_{B}$ is system capacity; $S_{D}$ is DG capacity. Suppose DG capacity is $\mathrm{S}$, and the short circuit current through the protection QF1 and QF2 respectively are:

$$
I_{Q F 1}=\frac{1}{6}, I_{Q F 2}=\frac{S}{5 S+25}
$$

By analysis, we know that with DG connected to the distribution network, when K1 meets short circuit fault, the short circuit current through the protection QF1 doesn't vary from the capacity, but the short circuit current through the protection QF2 increase with the DG capacity. When the DG capacity is large enough, it may lead to protection QF2's misoperation.

\section{Simulated analysis}

The simulation system model. To facilitate the research, this paper uses the constant impedance load model to represent the distribution network nodes. The DG and its control system is integrated into a module. By using the software PSCAD/EMTDC, this paper builds the typical model of $10 \mathrm{kV}$ distribution network [5], as shown in figure 2.

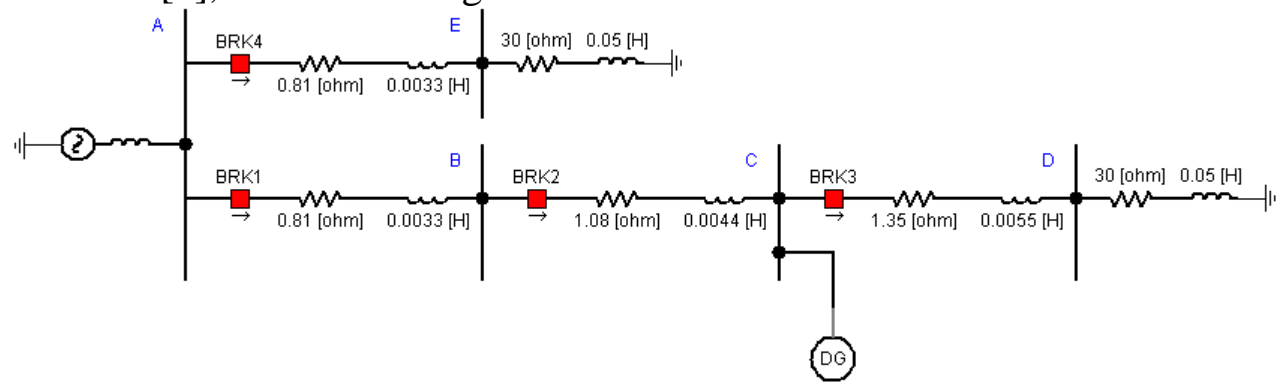

Figure 2 10kV distribution network

\section{Simulation and verification}

This example uses the simulation software PSCAD/EMTDC to simulate and analyze. Parameter settings are as follows: system capacity $S=100 \mathrm{MVA}$, under the maximum operation mode, distribute network's system impedance $\mathrm{X}=0.091 \Omega$, bus voltage $\mathrm{U}=10.5 \mathrm{kV}$, transmission line parameter $\mathrm{R}=0.27 \Omega / \mathrm{km}, \mathrm{X}=0.347 \Omega / \mathrm{km}$, Line length is set to $\mathrm{L}_{\mathrm{AB}}=\mathrm{L}, \mathrm{AE}=3 \mathrm{~km}, \mathrm{~L}_{\mathrm{BC}}=4 \mathrm{~km}, \mathrm{~L}_{\mathrm{CD}}=5 \mathrm{~km}$. This paper use the constant impedance model: $Z=(30+j 15.7) \Omega$, Equivalent to a single phase load 1.33MVA, reliable coefficient $\mathrm{K}_{\mathrm{rel}}=1.25$ 。

The simulation Settings are as follows:

Three phase short circuit fault happens at 0.2 second, the fault last 0.5 second, DG hasn't connected;

At 0.8 second, DG is connected to Bus C;

At 0.9 second, three phase short circuit fault happens again, lasting 0.5 second;

The simulation lasts 1.5 seconds.

The figure 3 is the situation. 


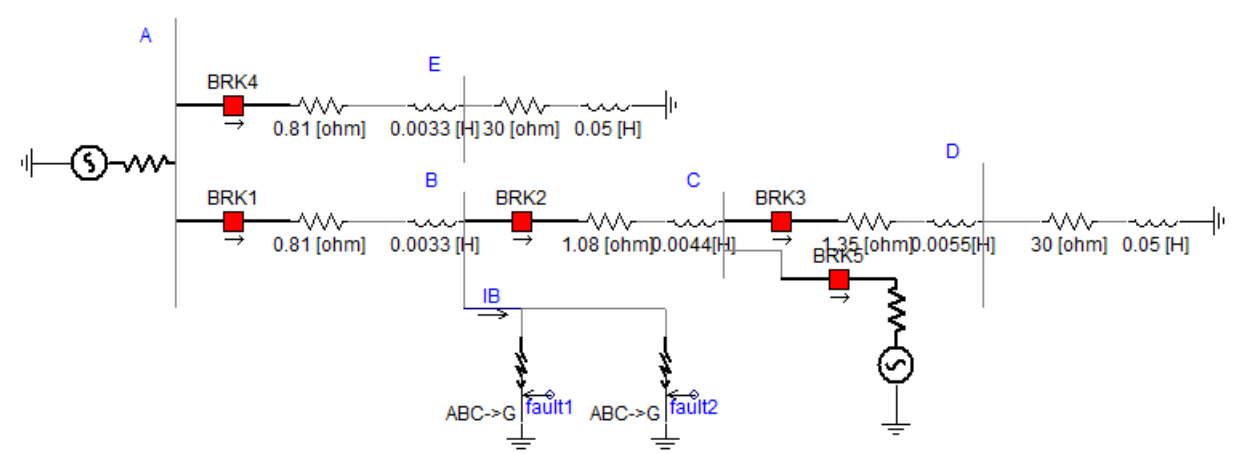

Figure 3: Bus B short circuit simulation model diagram

1, the current through BRK1 when Bus B short circuit

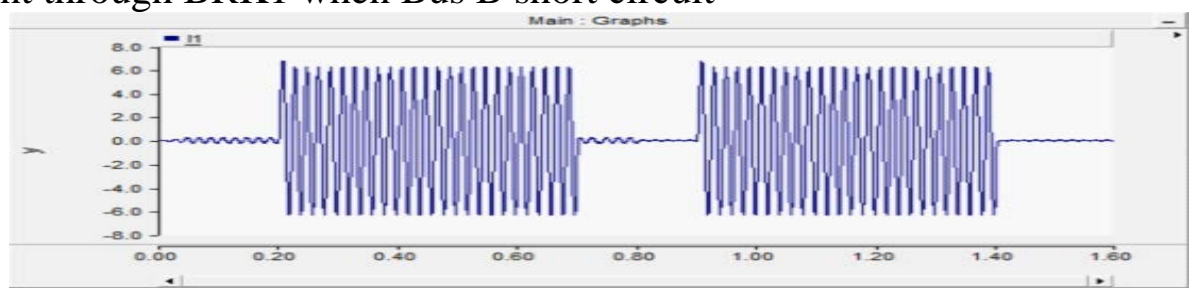

Figure 4 the current through BRK1 (single phrase)

$0.2 \mathrm{~s}-0.7 \mathrm{~s}$ : The short-circuit current before DG connected

$0.9 \mathrm{~s}-1.4 \mathrm{~s}$ : The short-circuit current after DG connected

Figure 4 illustrates that the connection of DG has no influence on the current through BRK1.

2, the current through BRK2 when Bus B short circuit

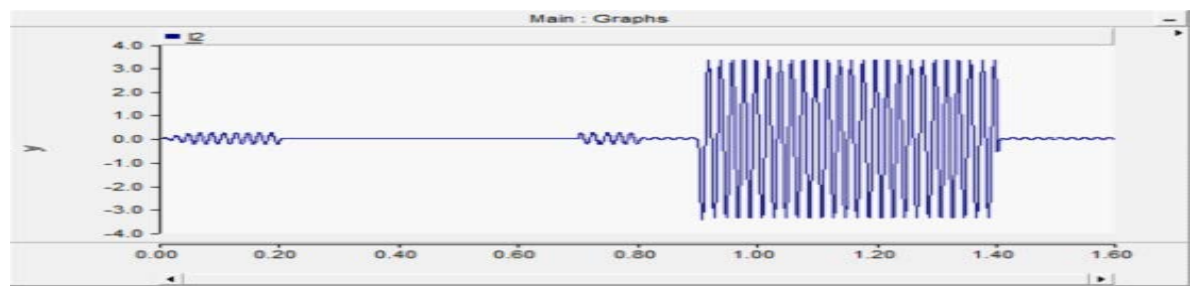

Figure 5 the current through BRK2 (single phrase)

$0.2 \mathrm{~s}-0.7 \mathrm{~s}$ : The short-circuit current before DG connected is 0 ;

$0.9 \mathrm{~s}-1.4 \mathrm{~s}$ : The short-circuit current before DG connected isn't 0 。

Figure 5 illustrates that the connection of DG will increase the current through BRK2.if the DG capacity connected to the grid is too large, break misoperation will happen.

3, the current through BRK3 when Bus B short circuit

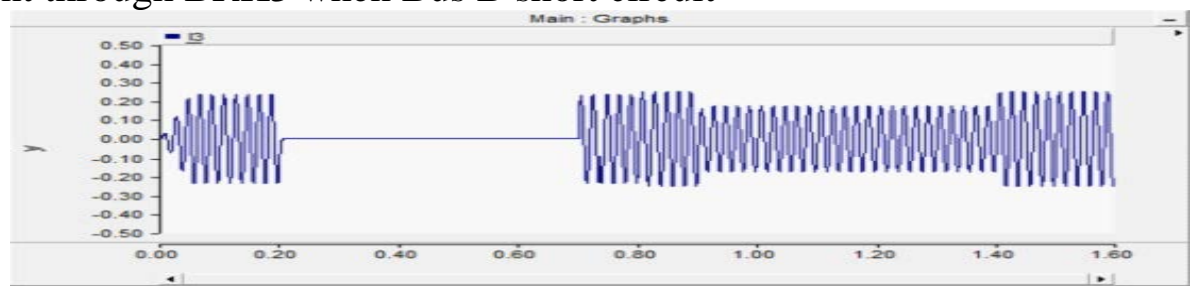

Figure 6 the current through BRK3 (single phrase)

$0.2 s-0.7 \mathrm{~s}$ : The short-circuit current before DG connected is 0 ;

$0.9 \mathrm{~s}-1.4 \mathrm{~s}$ : The short-circuit current before DG connected isn't 0 。

Figure 6 illustrates that the connection of DG will increase the current through BRK3.if the DG capacity connected to the grid is too large, break misoperation will happen.

4, the current through BRK4 when Bus B short circuit 


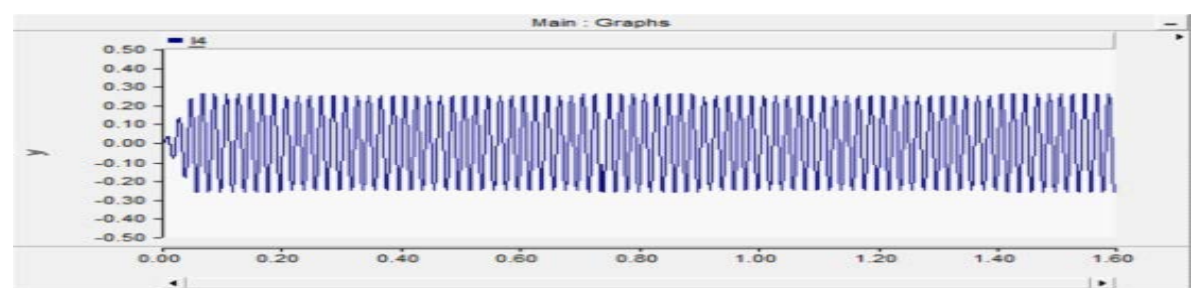

Figure 7 the current through BRK4 (single phrase)

$0.2 \mathrm{~s}-0.7 \mathrm{~s}$ : The short-circuit current before DG connected

$0.9 \mathrm{~s}-1.4 \mathrm{~s}$ : The short-circuit current after DG connected

Figure 7 illustrates that the connection of DG has no influence on the current through BRK4.

5, the current through Short circuit fault point when Bus B short circuit

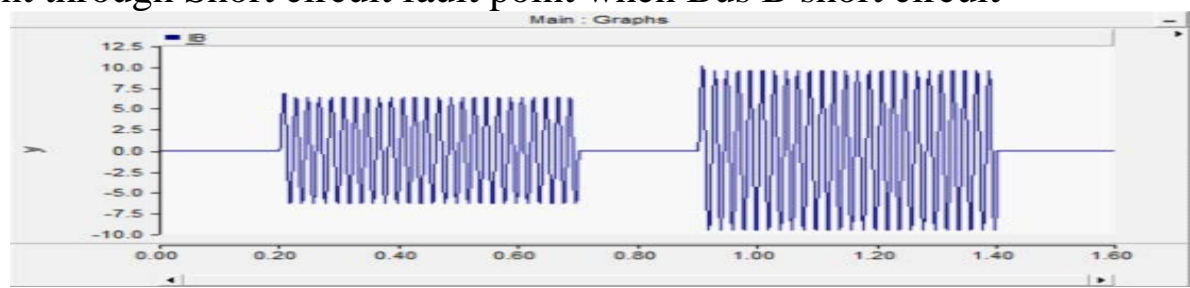

Figure 8 the current through short circuit fault point (single phrase)

$0.2 \mathrm{~s}-0.7 \mathrm{~s}$ : The short-circuit current before DG connected

$0.9 \mathrm{~s}-1.4 \mathrm{~s}$ : after the DG is connected, the current at short circuit point will increase significant.

To sum up, if the short circuit fault point is B that is DG's upstream, whether DG is connected to grid or not, the short circuit current through break BRk1and BRK4 don't change while the short circuit current through break BRK2 and BRK3 change from zero to a certain value. And break may meet misoperation when the capacity connected is too large.

\section{Summary}

After DG is connected to the distribution network, Power flow direction may change, short circuit current will also change due to the location of short circuit point and the capacity of DG. Especially, when the capacity is very large, the influence become much more obvious. Thus it bring about a series of new problems to the traditional distribution network protection. In order to deal with large-scale access of DG and meet the user's electric energy demand, new protection schemes which fit DG connecting to distribution network should be proposed.

\section{References}

[1] Jingliao Sun and Yongli Li. Distribution network protection scheme with Distributed generation [J]. Power System Automation, 2009, 33(1): 81-84

[2] Shanglin Zhao, Zaijun $\mathrm{Wu}$ and Minqiang Hu, Thinking about distributed generation and micro network [J] Protection Power System Automation, 2009, 33(3): 84-88

[3] Bin Li, Tianqi Liu, Xinyuan Li, The influence of the distributed power access to system voltage stability [J] Power System Technology, 2009, 33(3): 84-88

[4] Suqin yang,Nianhang Han and Nianhua Luo, Research overview on the impact of distributed generation connecting to regional power grid[J] Nanjing Engineering Journal (natural science edition) , 2011, 9(3): 49-54

[5] Liangzhen Lin and Lin Ye, Electromagnetic transient analysis software package PSCAD/EMTDC [J], Power System Technology, 2000, 24(1): 66-68 